\title{
Leukemia Inhibitory Factor Is Essential for Subventricular Zone Neural Stem Cell and Progenitor Homeostasis as Revealed by a Novel Flow Cytometric Analysis
}

\author{
Krista D. Buono ${ }^{\mathrm{a}, \mathrm{b}}$ Daimler Vadlamuri ${ }^{\mathrm{a}}$ Qiong Gan ${ }^{\mathrm{a}}$ Steven W. Levison ${ }^{\mathrm{a}}$ \\ a Department of Neurology and Neuroscience, New Jersey Medical School, University of Medicine and Dentistry of

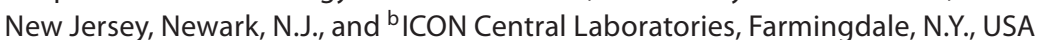

\section{Key Words}

Neurogenesis · Glial progenitors • Gliogenesis •

Subventricular zone $\cdot$ Oligodendrocyte

\begin{abstract}
Stem cells rely on extracellular signals produced by the niche, which dictate their ability to self-renew, expand and differentiate. It is essential to have sensitive and reproducible methods of either quantifying or isolating these stem cells and progenitors to understand their intrinsic properties and how extrinsic signals regulate their development. However, stem cells are difficult to distinguish from multipotential progenitors, which may look and act like them. Here we define a 4-color flow cytometry panel using CD133, LeX, CD140a, NG2 to define a neural stem cell (NSC) as well as 4 classes of multipotential progenitors and 3 classes of bipotential progenitors, several of which have not been described previously. We performed gain and loss of function studies for leukemia inhibitory factor (LIF) and showed a depletion of NSCs, a subset of multipotential neural precursors and immature oligodendrocytes in LIF null mice. Gain of function studies showed that LIF increased the abundance of these precursors. Our studies also show that these NPs have differential requirements for LIF and ciliary neurotroph-
\end{abstract}

ic factor (CNTF) and for epidermal growth factor (EGF), fibroblast growth factor (FGF-2) and platelet-derived growth factor (PDGF) for their propagation in vitro. Surprisingly, the related cytokine, CNTF, was less potent than LIF in increasing the NSCs and more potent than LIF in increasing the PDGF responsive multipotential precursors. Finally, we show that LIF increases the expression of the core transcription factors: KIf4, Fbx15, Nanog, Sox2 and c-Myc. Altogether our FACS (fluorescence-activated cell sorter) analyses reveal that the neonatal subventricular zone is far more heterogeneous than previously suspected and our studies provide new insights into the signals and mechanisms that regulate their self-renewal and proliferation.

Copyright $\odot 2012$ S. Karger AG, Basel

\section{Introduction}

Virtually all of the neurons and glia that populate the mature brain arise from neural precursors (NPs) that reside immediately adjacent to the lateral ventricles. By parturition, the ventricular zone (VZ) has regressed, but NPs persist within the subventricular zone (SVZ). The SVZ achieves its maximal size and heterogeneity during the neonatal period, when the neonatal brain is in a dynam-

\section{KARGER}

Fax +41613061234

E-Mail karger@karger.ch

www.karger.com
(C) 2012 S. Karger AG, Basel

$0378-5866 / 12 / 0345-0449 \$ 38.00 / 0$

Accessible online at:

www.karger.com/dne
Steven W. Levison

Laboratory for Regenerative Neurobiology, NJMS-Cancer Center H1226

UMDNJ-New Jersey Medical School

Newark, NJ 07103 (USA)

E-Mail steve.levison@umdnj.edu 
ic state of development. With the recent discovery that adult olfactory bulb neurogenesis in the human brain likely ceases after 18 months of age, there is increased interest in studying the NPs of the neonate [1].

Leukemia inhibitory factor receptor (LIFR) is an important signaling molecule that influences the heterogeneity within the germinal zones. At E11.5 when the VZ and $S V Z$ are both present, the VZ robustly expresses the LIFR while the SVZ is deficient [2]. Within the primitive $\mathrm{VZ}$ there is a symmetric expansion of fibroblast growth factor-2 (FGF-2)-responsive neural stem cells (NSCs) [2]. During fetal development, the cells of the choroid plexus begin to secrete many small molecules that include leukemia inhibitory factor (LIF) and ciliary neurotrophic factor (CNTF) that signal through the LIFR. LIF/CNTF creates a gradient within the germinal zones that establishes the distinct layers of VZ and SVZ and sustains selfrenewal of the NPs [2]. As SVZ cells begin to expand exponentially during the latter third of fetal development epidermal growth factor (EGF)-responsive NPs emerge. Thus, the SVZ becomes a mixture of FGF2- and EGFresponsive precursors [3]. Also coincident with the emergence of the EGF-responsive NPs is the shift from neurogenesis to astrogliogenesis and then to oligodendrogenesis.

Many neuroscientists have sought to isolate and characterize the NSC. Studies have identified numerous cellsurface antigens that are expressed by subsets of NPs that include CD133, Lewis-X (LeX) and NG2 proteoglycan [48]. Unfortunately, these markers are not restricted to NPs. As NSCs fail to express unique lineage markers, investigators have implemented negative selection strategies using neuronal precursor markers like cholera toxin B subunit and tetanus toxin fragment $\mathrm{C}$ along with glial progenitor antigens: A2B5, O4 and O1 [9]. However, separations that fail to include CD133 and LeX are of limited utility [10].

With the discovery that adult NSCs express GFAP, recent studies have used hGFAP-GFP mice to study the NSCs $[11,12]$. Unfortunately, neonatal NSCs do not express GFAP since the transition from GFAP- to GFAP+ NSCs occurs during the second week of life; thus, these mice have limited utility for studies of embryonic or neonatal NSCs [13]. Here we report a novel 4-color flow cytometry and fluorescence-activated cell sorter (FACS) protocol that enables the identification and characterization of a NSC, 4 classes of multipotential progenitors and 3 classes of bipotential progenitors and have evaluated their requirement for LIF signaling for their growth and maintenance. These studies reveal that the neonatal SVZ is far more heterogeneous than previously suspected and they provide new insights into the signals and mechanisms that regulate their self-renewal and proliferation.

\section{Materials and Methods}

C57BL/6 postnatal day 7 (P7) neonatal mice generated from breeders purchased from Jackson Laboratories (Bar Harbor, Me., USA) were used for neurosphere studies, FACS analysis and studies on the cellular composition of the adult SVZ. CD-1 background LIF P11 heterozygotes and nulls (bred with CD-1 mice purchased from Charles River Laboratories (Wilmington, Mass., USA) were genotyped using primers and the polymerase chain reaction-based method, along with age-matched wild-type neonates for flow cytometric analysis. All experiments were performed in accordance with research guidelines set forth by the IACUC committee of the New Jersey Medical School.

\section{Neurosphere Experiments}

Spheres were prepared from P7 neonates using standard techniques. After 7 days in vitro, spheres were collected, digested with $70 \%$ strength Accutase (Millipore, Billerica, Mass., USA) and plated at $5 \times 10^{4}$ cells $/ \mathrm{cm}^{2}$ for secondary $\left(2^{\circ}\right)$, tertiary $\left(3^{\circ}\right)$ or quaternary $\left(4^{\circ}\right)$ spheres. Spheres were cultured in chemically defined medium supplemented with $20 \mathrm{ng} / \mathrm{ml}$ EGF (PeproTech, Rocky Hill, N.J., USA) and $10 \mathrm{ng} / \mathrm{ml} \mathrm{FGF2} \mathrm{(PeproTech)} \mathrm{with} 2 \mathrm{ng} / \mathrm{ml}$ heparin (referred to as EF). Recombinant mouse LIF (rmLIF; Millipore) and recombinant rat CNTF ( $r$ CNTF; R\&D Systems, Minneapolis, Minn., USA) were used at $5 \mathrm{ng} / \mathrm{ml}$, while soluble receptor alpha for $\mathrm{rrCNTF}$ were used at $100 \mathrm{ng} / \mathrm{ml}$. Cells were grown for 6-7 days prior to analysis. A sphere was defined as a free-floating, cohesive cluster that was at least $30 \mu \mathrm{m}$ in diameter, although the majority of spheres were larger in size. Plates were gently shaken to distribute the spheres before counting. Five random $\times 10$ fields were counted per well and 6 wells were evaluated per group. The frequency of sphere-forming cells was calculated for $3^{\circ}$ and $4^{\circ}$ (fig. 3 ) by the average number of spheres per field, the area of the field and the area of the well using a Ziess Observer.Z1. Sphere volume was calculated using Ziess Axiovision software.

\section{Neurosphere Differentiation}

$3^{\circ}$ spheres were plated onto chamber slides previously coated with $1 \%$ poly- $d$-lysine $(\mathrm{w} / \mathrm{v})$ and $10 \mu \mathrm{g} / \mathrm{ml}$ laminin, in ProN with $0.5 \%$ FBS without growth factors. After 5-7 days, chamber slides were stained using $\mathrm{O} 4$ culture supernatant (1:20) in 10\% lamb serum in DMEM/F12 with $15 \mathrm{mM}$ HEPES at room temperature (RT) for $45 \mathrm{~min}$, washed in $\mathrm{BCH}(10 \%$ newborn bovine serum in DMEM/F12 with HEPES) and then incubated for $30 \mathrm{~min}$ in GAM IgM lissamine rhodamine sulfonyl chloride (1:200; Jackson ImmunoResearch, West Grove, Pa., USA). Cells were fixed in 3\% paraformaldehyde, quenched with $100 \mathrm{~mm}$ glycine, rinsed with PBS and then permeabilized with methanol for $20 \mathrm{~min}$ at $-20^{\circ} \mathrm{C}$. Cells were blocked in TGB superblock (0.3\% Triton X-100, 10\% goat serum, $10 \%$ bovine serum albumin in Tris-buffer) for $45 \mathrm{~min}$ and immunostained using anti- $\beta$-tubulin III (TUJ1, 1:300; Covance, Princeton, N.J., USA) and anti-GFAP (1:500; Dako, Carpenteria, Calif., USA) in TGB diluent $\mathrm{O} / \mathrm{N}$ at $4^{\circ} \mathrm{C}$. After washing thoroughly, cells were incubated for $30 \mathrm{~min}$ at RT in GAM dylight 
488 IgG2a for TuJ1 and GAR dylight 649 IgG for GFAP (both at 1:300; Jackson ImmunoResearch, West Grove, Pa., USA). Cells were coverslipped with ProLong Gold with DAPI (4',6-diamidino2-phenylindole; Invitrogen, Carlsbad, Calif., USA). Images of stained cells were collected using a SenSys cooled-coupled device camera (CRI) interfaced with IPLab scientific imaging software (Scanalytics) on an Olympus AX-70 microscope.

\section{Flow Cytometric Sample Preparation}

$2^{\circ}$ or $3^{\circ}$ spheres were dissociated with 0.2 Wünsch unit (WU)/ $\mathrm{ml}$ of Liberase DH (Roche) and $250 \mu \mathrm{g}$ of DNase1 (Sigma) in PGM solution (PBS with $1 \mathrm{mM} \mathrm{MgCl}_{2}$ and $0.6 \%$ dextrose) and were incubated in a $37^{\circ} \mathrm{C}$ water bath for $5 \mathrm{~min}$ with gentle shaking. Equal volume of PGM was added and spheres were placed on shaker (LabLine) at $220 \mathrm{rpms}$ at $37^{\circ} \mathrm{C}$ for $10 \mathrm{~min}$. SVZs were dissociated with $0.45 \mathrm{WU} / \mathrm{ml}$ of Liberase DH and $250 \mu \mathrm{g}$ of DNase1 in PGM and were shaken at $220 \mathrm{rpm}$ at $37^{\circ} \mathrm{C}$ for $30 \mathrm{~min}$. After enzymatic digestion, liberase $\mathrm{DH}$ was quenched with $10 \mathrm{ml}$ of PGB (PBS without $\mathrm{Mg}^{2+}$ and $\mathrm{Ca}^{2+}$ with $0.6 \%$ dextrose and $2 \mathrm{mg} / \mathrm{ml}$ fraction $\mathrm{V}$ of BSA-Fisher) and cells were centrifuged for $5 \mathrm{~min}$ at $300 \mathrm{~g}$. Cells were dissociated by repeated trituration, collected by centrifugation, counted using ViCell (Beckman Coulter, Miami, Fla., USA) and diluted to at least $10^{6}$ cells per $50 \mu$ of PGB. All staining was performed in $96 \mathrm{~V}$-bottom plates using $150 \mu \mathrm{l}$ volume. For surface marker analysis, cells were incubated in PGB for $25 \mathrm{~min}$ with antibodies against CD24-PE/Cy7 (1:300, M1/69; BioLegend), Lewis-X (1:20, LeX/CD15, MMA; BD Bioscience), CD133-APC (1:50,13A4; eBioscience), CD140a (1:400, APA5; BioLegend) and NG2 Chondroitin Sulfate Proteoglycan (1:50, AB5320; Millipore). Cells were washed with PGB by centrifugation at $300 \mathrm{~g}$. Antimouse IgM PerCP-eFluor 710 (1:200; eBioscience) was used for LeX, while goat anti-rabbit IgG Alexa Fluor 700 (1:100; Invitrogen) was used for NG2. Secondary antibodies and DAPI (for spheres - live analysis; Sigma) or LIVE/DEAD fixable Violet (for SVZs - fixed cell analysis; Invitrogen) were incubated in PGB for 20 min. DAPI or LIVE/DEAD was used for dead cell exclusion. To analyze oligodendrocyte lineage, we used a panel comprised of $\mathrm{O} 4$ (1:5) detected with anti-mouse IgM PerCP-efluor 710 (1:200). Cells were washed with PGB by centrifugation at $300 \mathrm{~g}$. Cells from SVZ were fixed with $1 \%$ ultra-pure formaldehyde $(50,000$; Polysciences, Inc.) for $20 \mathrm{~min}$, collected by centrifugation for $9 \mathrm{~min}$ at $609 \mathrm{~g}$, resuspended in PBS w/o $\mathrm{Mg}^{2+}$ and $\mathrm{Ca}^{2+}$ and stored at $4^{\circ} \mathrm{C}$ for next day analysis. All sample data were collected on the BD LSR II (BD Biosciences Immunocytometry Systems).

\section{Flow Cytometric Gating}

Gating and data were analyzed with FlowJo software (Tree Star, Inc.). Matching isotype control for all antibodies were used and gates were set based on these isotype controls [14]. Overall flow cytometric data used a flow cytometric gating profile of debris, dead cell and doublet exclusion. A positive control was used for dead cell exclusion by heating cells to $95^{\circ} \mathrm{C}$ for $3-5 \mathrm{~min}$, filtering, adding DAPI or LIVE/DEAD and then placing on ice prior to analysis. The gating strategy for neurospheres and SVZ used is as follows: (gate 1) live cell scatter: SSC-A versus FSC-A; (gate 2) live cell gating with DAPI or LIVE/DEAD exclusion: FSC-A versus DAPI or LIVE/DEAD; (gate 3) single cell gating to exclude doublets: FSC-A versus FSC-W; (gate 4) CD140a-PE versus NG2Alexa Fluor 700; (gate 5) CD133-APC versus LeX-PerCP eFluor 710 .

\section{Cell Sorting}

Dissociation and cell staining was performed as described above, with the exception that $15-\mathrm{ml}$ falcon tubes were used instead of a 96-well plate and large volume washes were done. For sorting, cells were resuspended at $4 \times 10^{6} / \mathrm{ml}$ in PGB. Cells were isolated by FACSVantage ${ }^{\mathrm{TM}} \mathrm{SE}$, using 9 psi pressure and $90 \mu \mathrm{m}$ nozzle aperture, while its regular sheath fluid was replaced with sterile PGB. Cells were collected with polypropylene tubes in $70 \%$ neurosphere-conditioned medium (CM) plus EF and kept on ice. Cells were centrifuged at $300 \mathrm{~g}$ and plated into 8-well chamber slides coated with $1 \%$ poly- $d$-lysine and $10 \mu \mathrm{g} / \mathrm{ml}$ laminin. Cells were plated at about 1,000 cells (NSC), 8,000 (MP4), or about 5,000 cells/well and then expanded in either 70\% CM plus EF or ProN plus PDGF-AA with FGF2-heparin. Medium was changed every other day. After 4-6 days, growth factors were withdrawn and cells were differentiated in DMEM/F12-HEPES containing B27 supplement (Gibco) with 0.5\% FBS for 10 days. Medium changed every 2 days. Immunofluorescence imaging was performed as described above using O4, TuJ1 and GFAP. Chamber slides were also stained using A2B5 supernatant (1:5), GD3 (R24, 1:5; gift from Dr. James E. Goldman), GFAP, O4, GD3 and GFAP.

\section{Flow Cytometry Analysis for Adult Mouse SVZs}

Adult mouse SVZs were dissociated with $0.5 \mathrm{WU} / \mathrm{ml}$ of liberase DH and $250 \mu \mathrm{g} / \mathrm{ml}$ of DNaseI in PGM with agitation at 220 $\mathrm{rpm}$ at $37^{\circ} \mathrm{C}$ for $1 \mathrm{~h}$. After enzymatic digestion, liberase $\mathrm{DH}$ was quenched with $10 \mathrm{ml}$ of PGB and cells were centrifuged for $5 \mathrm{~min}$ at $300 \mathrm{~g}$. Cells were dissociated by repeated trituration, then filtered through a $100-\mu \mathrm{m}$ cell strainer, washed in $25 \mathrm{ml}$ PGB and collected by centrifugation. To remove dead cells and debris, the cell suspension was layered onto 22\% Percoll in PGB and centrifuged for $10 \mathrm{~min}$ at $500 \mathrm{~g}$ [15]. Cells were resuspended in PGM and processed for flow cytometry as described above.

\section{Quantitative Real-Time PCR Analysis}

Tertiary spheres were collected after treatment from EF and EF plus 5 and $20 \mathrm{ng} / \mathrm{ml}$ of rmLIF. Spheres were centrifuged, washed with PBS, snap frozen on dry ice in TRIzol reagent (Invitrogen) and stored at $-80^{\circ} \mathrm{C}$. Total RNA was extracted by homogenizing ice-thawed TRIzol spheres, centrifuging and then following the RNeasy Mini protocol (QIAGEN). cDNA was generated using SuperScript III reverse transcriptase (Invitrogen), according to the manufacturer's instructions for calibrator (pooled P5 neonatal SVZ cDNA), $18 \mathrm{~S}$ rRNA (Ambion, Inc.) and sphere sample. cDNA was quantified using Nanodrop (ND-1000; Thermo Scientific) and $100 \mathrm{ng}$ of cDNA was used in each qPCR reaction well. QuantiTect SYBR Green c-Myc, distal-less homeobox 2 (Dlx2), F-box protein 15 (Fbx15), $\alpha 1,3$-fucosyltransferase IX (Fut9), krueppellike factor 4 (Klf4), Nanog, sex-determining region Y-box 1 (Sox1) and Sox 2 primers according to the manufacturer's protocol were utilized for quantitative real-time polymerase chain reaction (qPCR), using the ABI Prism 7300 Sequence Detection System (Applied Biosystems). 18S RNA was used as the internal, endogenous normalization control. Relative quantification was evaluated by the $\Delta \Delta \mathrm{Ct}$ method to measure expression of genes reported.

Statistical Analysis

All data were expressed as means \pm SEM and were analyzed using one-way ANOVA followed by Tukey's post hoc analysis (Graphpad Prism 4 software). 


\section{Results}

Multi-Panel Isolation of SVZ NSC and Seven

Phenotypically Distinct Progenitors

Multipotential NSCs that are CD133+LeX+Lin- reside within the SVZ [6, 7]. In addition to these NSCs, the SVZ contains a mosaic of different developmentally staged precursors and lineage-restricted cell types [16-18]. Using FACS, investigators in the hematopoietic stem cell field have identified, purified and constructed a complex lineage tree for the formed cells of the blood. Progress has been made in studying 'neuropoiesis'; however, there is no consensus for the types of NPs that exist nor is there a widely used panel of markers to classify the different types of precursors that reside within the brain's germinal matrices. Therefore, to enable a more complete characterization of the precursors of the SVZ, we evaluated several panels of cell-surface markers.

The panel that proved most informative in distinguishing between NSCs, multi- and bi-potential progenitors and unipotential progenitors was comprised of the following markers: prominin-1: CD133, Lewis-X: LeX, heat stable antigen: CD24, NG2 chondroitin sulphate proteoglycan, and platelet-derived growth factor receptor- $\alpha$ (PDGFR $\alpha$ ): CD140a. To enrich for periventricular precursors dissociated cells from P7 neonatal mouse SVZs were amplified as neurospheres in medium containing EGF and FGF-2 (EF). The neurospheres were dissociated with liberase-DH, a gentle enzymatic reagent that increases dissociation efficiency, viability and cellsurface antigen retention (particularly CD133 and CD24) [19], and incubated with CD133-APC, LeX-PerCP eFluor 710, CD24-PE/Cy7, CD140a-PE, NG2-Alexa 700 and DAPI. We found that all NPs expressed CD24, and thus, CD24 was either ignored or eliminated from the panel. Debris, dead cells and doublets were excluded from analysis using DAPI and forward scatter gates while gates were set using isotype controls. From 9 independent FACS studies, 8 phenotypically different NPs were sorted using a two-gate strategy where the first gate was CD140a versus NG2 (fig. 1A1, quadrants $\mathrm{A}, \mathrm{B}$ and $\mathrm{C}$ ) and the second gate was CD133 versus LeX (fig. 1B1-D1, boxes 1-8). The first distinct population was NG2+CD140a+ (fig. 1A1, box A) that were classified separately into three subpopulations: CD133+LeX+ (box 1), CD133-LeX+ (box 2) and CD133-LeX- (Box 3). The second population was NG2+CD140a- (fig. 1A1, box B), that was segmented into three subpopulations: CD133+LeX+ (box 4), CD133LeX+ (box 5) and CD133-LeX- (box 6), while the third population was double negative for NG2/CD140a (fig. 1A1, box C) which could be segmented into two subpopulations: CD133+LeX+ (box 7) and CD133-LeX+ (box 8).

To determine the developmental potential of these eight subpopulations, sorted cells were plated onto poly$d$-lysine and laminin-coated chamber slides at low density and expanded with growth factors. Initially, all subpopulations were plated with $70 \%$ neurosphere-conditioned medium supplemented with EF; however, some precursors could not be expanded in EF. Those sorted precursors that responded to EF included CD133+LeX+ NG2-CD140a-,CD133-LeX+NG2-CD140a-,CD133+LeX+ NG2+CD140a- and CD133-LeX+NG2+CD140a-. Those precursors that expressed CD140a+ were expanded in PDGF-AA and FGF-2 (with the exception of CD133LeX-NG2+CD140a- which were also expanded using PDGF-AA and FGF-2). The sorted CD133+LeX+NG2+ $\mathrm{CD} 140 \mathrm{a}+$ progenitors required, in addition to PDGF-AA and FGF-2, B27-supplemented medium containing 0.5\% FBS. After 4-6 days, all eight sorted NPs formed spheres (fig. 1E1-L1). The CD133+LeX+NG2-CD140a- precursors formed the smallest spheres (fig. 1E1-L1).

To determine potentiality, we differentiated the colonies formed from these NPs by withdrawing the growth factors and maintaining them in $0.5 \%$ FBS for an additional 10 days. Triple immunostaining was performed for $\beta$ III-tubulin (TUJ1; for immature neurons), GFAP (for astrocytes) and $\mathrm{O} 4$ (for oligodendrocytes). Additionally, cells were stained for TUJ1, GFAP and GD3 (b-series ganglioside, for immature cells [20]); or GFAP, GD3 and O4 or GFAP, GD3 and A2B5 (for immature cells and also biand uni-potential glial-restricted progenitors [21]). Five of the 8 subpopulations were multipotential precursors (MP), yielding neurons, oligodendrocytes and astrocytes: CD133+LeX+NG2-CD140a- (NSC; fig. 1E2), CD133LeX+NG2-CD140a- (MP1; fig. 1F2), CD133+LeX+NG2+ CD140a- (MP2; fig. 1G2), CD133+LeX+NG2+CD140a+ (MP4; fig. 1H2) and CD133-LeX+NG2+CD140a+ (referred to as PDGFR $\alpha$-FGF2-responsive MP cell: PFMP; fig. 1I2). Spheres differentiated from CD133-LeX+NG2+ CD140a- were bipotential, producing either astrocytes and neurons (referred to as bipotential neuronal-astrocytic precursor, BNAP; fig. 1J2, J3) or astrocytes and oligodendrocytes (referred to as glial-restricted precursor, GRP1; fig. 1J4, J5). Two other phenotypically distinct subpopulations were GRPs that produced oligodendrocytes and astrocytes: CD133-LeX-NG2+CD140a+ (GRP3; fig. $1 \mathrm{~K} 2, \mathrm{~K} 3$ ) and CD133-LeX-NG2+CD140a- (GRP2; fig. 1L2, L3). In separate studies, we sorted NPs directly from the neonatal SVZ. The progeny that each SVZ pre- 


\section{Fluorescence Activated Cell Sorting Strategy}
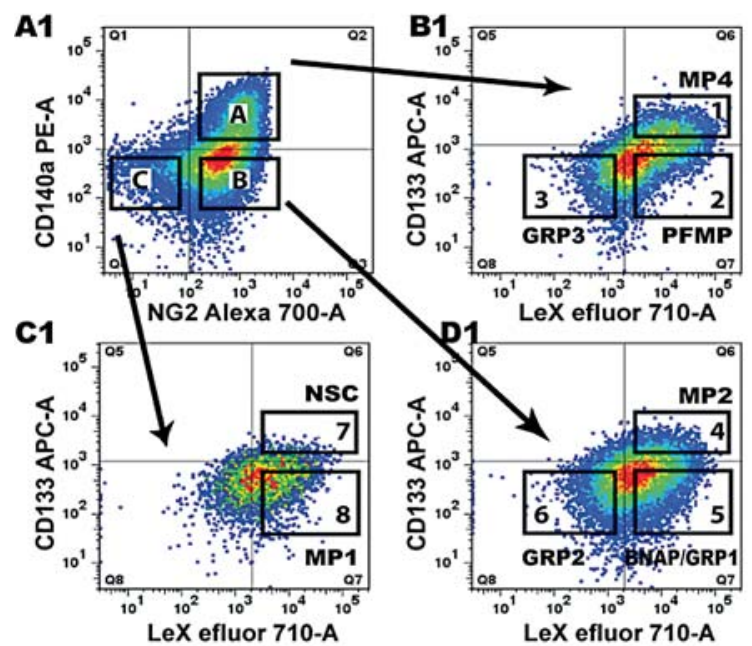

Isotype Controls
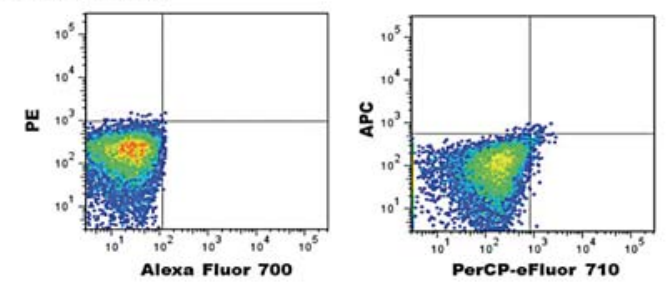

\section{Multipotential Precursors}
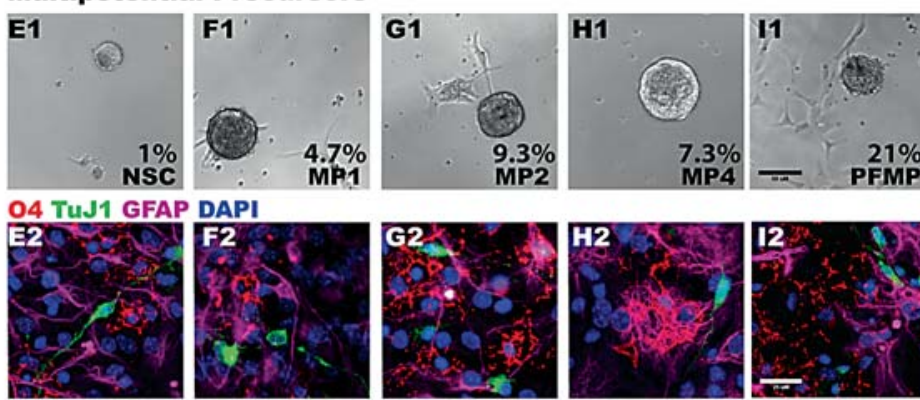

Bipotential Precursors / Glial-Restricted Precursors
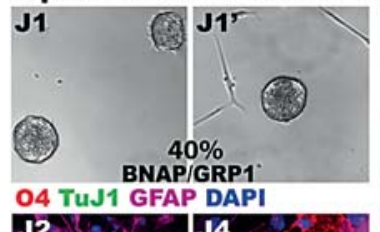

O4 TuJ1 GFAP DAPI
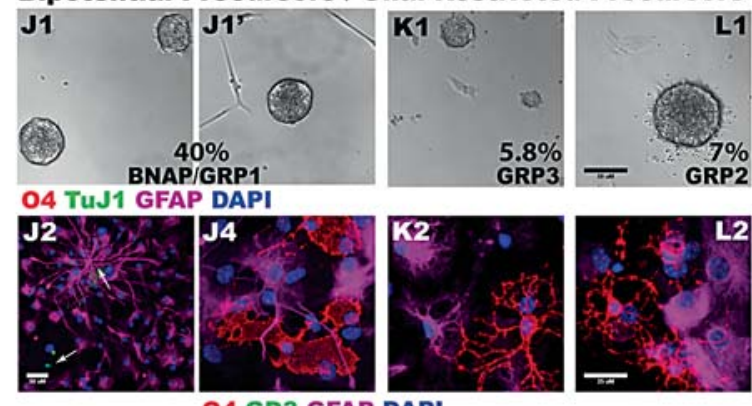

L1
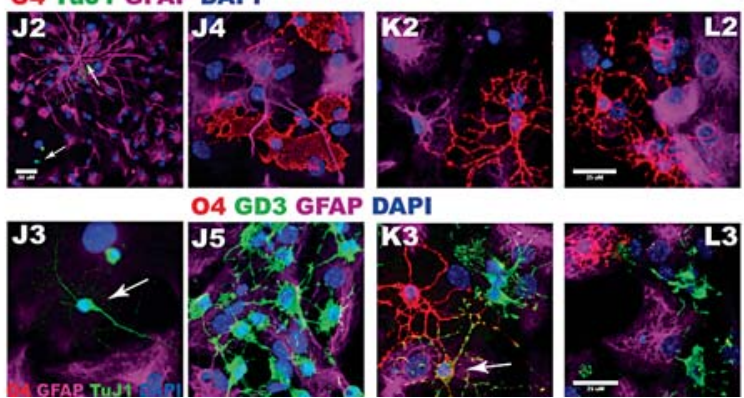

Fig. 1. Diversity of sorted mouse neonatal neural precursors. A1D1 Secondary neurospheres from P7 C57BL/6 mouse pups were dissociated with liberase-DH and sorted by FACS using a twogate strategy. Debris and dead cells were excluded using DAPI and positive staining was established using isotype controls. After gating on CD140/NG2 (A1), cells were separated based on intensity of CD133/LeX. B1-D1 Eight cell types within the boxes in B1-D1 were sorted and analyzed. E1-L1 Sorted cells were grown on poly$d$-lysine and laminin-coated chamber slides in either EGF+FGF2 (NSCs, MP1, MP2 and BNAPs/GRP1) or PDGF-AA+FGF2 (MP4, PFMP, GRP3 and GRP2). Panels depict phase-contrast images of spheres at 4-6 DIV. E2-L2 Progeny of multipotential precursors.
Growth factors were removed and cells were differentiated for 10 DIV and then fixed and immunostained for oligodendrocytic (O4; red), neuronal (TuJ1; green) and astrocytic (GFAP; purple) markers. J2, J3, J4, K2, L2 Progeny of bipotential progenitors stained for O4, GFAP and TuJ1. Arrows in $\mathbf{J} 2$ identify TuJ1+ cell and GFAP+ radial glial-like cells. Arrow in J3 identifies a TuJ1+ cell. J5, K3, L3 Progeny of bipotential progenitors stained for O4 (red), GD3 (green) and GFAP (purple). Arrow in K3 indicates coexpression of GD3 and O4 observed on an immature oligodendrocyte. Scale bars represent: $50 \mu \mathrm{m}$ in panels E1-I1; $25 \mu \mathrm{m}$ for panels E2-L3. Data were aggregated from 9 independent FACS studies. cursor produced was the same, with the exception that cells with the cell surface phenotype of GRP2s when sorted directly from the SVZ differentiated astrocytes and oligodendrocytes; however, some of the colonies produced from these NG2+ precursors also produced neurons (data not shown). Thus, we will refer to this population of cells, which were directly sorted from the SVZ, as MP3/GRP2s (CD133-LeX-NG2+CD140a-).

Amongst the progeny from these NPs, a variety of previously described glial subtypes types were seen. For ex- ample, a distinct A2B5-GD3+GFAP+ radial glial-like cell (fig. 2A1, A2) with end-feet (fig. 2B1, B2) was obtained when MP1 and BNAP/GRP1 colonies were differentiated. This radial glial-like cell was first described by Bonaguidi et al. [22] from SVZ NPs maintained in LIF. Adhered to these radial-glial like cells were cells with migratory profiles (fig. 2C1, C2). A second unique cell was a large flat cell that possessed large nuclei and had multiple, thinspike-like projections; similar to cells previously described [23]. These flat cells were identified as A2B5+ or 
Radial Glia-like Astrocyte
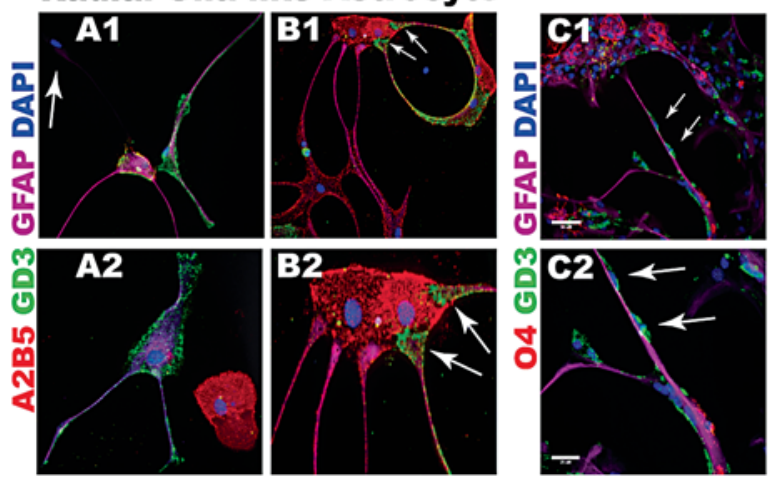

Fig. 2. Astroglial progeny of sorted mouse neural precursors. Secondary neurospheres from P7 C57BL/6 mouse pups were dissociated with liberase-DH and sorted by FACS and differentiated as described in figure 1. A-E Representative images of radial gliallike astrocytes from NSC, MP1 and BNAP/GRP1. Cells were immunostained for A2B5 (red), GD3 (green) and GFAP (purple). A1-A2 Depict end-feet of a radial glial-like cell contacting an A2B5+ dividing cell (arrows). B1-B2 Depict radial glial-like cell in an astrocyte (GFAP-purple)- and oligodendrocyte (O4 red)rich area. Arrows in C2 indicate two immature GD3+ (green) cells

GD3+ (fig. 2D1, D2) or A2B5+GD3+GFAP \pm (fig. 2D3, D4) and often resided within dense heterogeneous groups (fig. 2D5, D6). Small A2B5+GD3+GFAP- cells, that were presumably oligodendrocyte precursors, were found on top of these glial cells (fig. 2D6). These large flat cells were observed within colonies containing neurons or oligodendrocytes (fig. 2E1, E2). However, none of the flat cells were $\mathrm{O} 4+$. These large flat cells persisted even after 10 days of growth factor withdrawal. The two glial-restricted precursors (GRP2 and GRP3) generated $\mathrm{A} 2 \mathrm{~B} 5^{\mathrm{lo}} \mathrm{GD} 3-$ $\mathrm{GFAP}+$ (immature astrocytes) and A2B5+GD3+GFAPor $\mathrm{O} 4 \pm \mathrm{GD} 3+\mathrm{GFAP}-$ (immature oligodendrocytes; fig. 2E2, fig. 1J5, K3, L3). To our knowledge, this is the first description of the isolation of SVZ precursors capable of producing these radial glia-like and large GD3+ flat cells.

NSA Reveals Expansion, Sustained Self-Renewal and Increased Multipotentiality with LIF Treatment

LIF is known for its pleiotropic effects on various cell types and at many stages of nervous system development. LIF has been shown to promote the survival, expansion and/or self-renewal of human [24], rodent embryonic [25] and adult mouse putative NSCs [26]. The NSA was used to assess the effects of LIF on expansion, self-renewal and fate of neonatal SVZ precursors and these studies used

\section{Large, Flat Precursors}
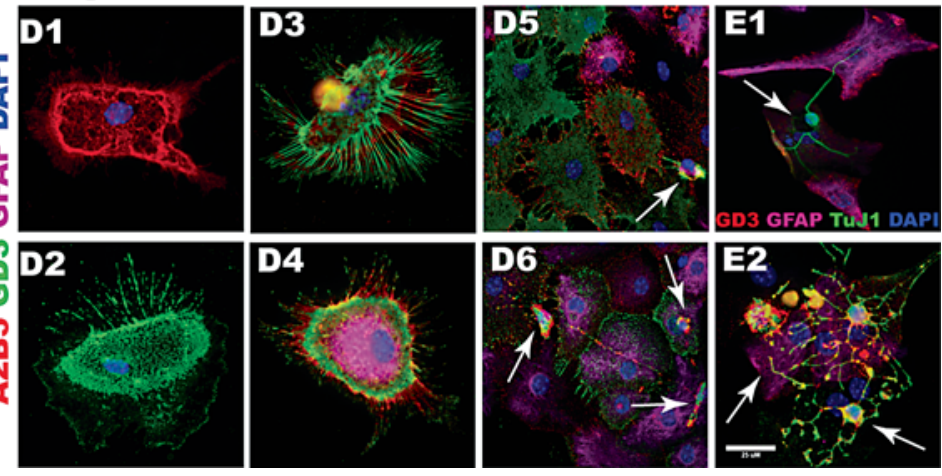

on a radial process. D-E Large, flat precursors immunostained with A2B5 (red), GD3 (green) and GFAP (purple). D1-D6 Arrows indicate small immature cells on top of flat cells. E1 A small colony of flat cells and a neuron (GD3-red, TUJ1-green, GFAP-purple). Arrow points to the neuron. E2 A colony of flat cells, immature astrocytes (A2B5+GD3-GFAP+, arrow) and immature oligodendrocytes (A2B5+GD3+GFAP-, arrow). Nuclei in images were stained with DAPI (blue). Scale bars $=50 \mu \mathrm{m}$ for panels C1, C2, and $25 \mu \mathrm{m}$ for panels A-B, D, E. Data were aggregated from 9 independent FACS studies.

high doses of LIF (20 $\mathrm{ng} / \mathrm{ml}$ or greater) to obtain maximum responses $[25,26]$. However, LIF is known to exert dose-dependent effects; therefore, we evaluated two doses within $(5 \mathrm{ng} / \mathrm{ml})$ and above $(20 \mathrm{ng} / \mathrm{ml})$ the $\mathrm{K}_{\mathrm{d}}$ range of the LIF/LIFR/gp130 complex [27]. Stimulating NPs with 5 or $20 \mathrm{ng} / \mathrm{ml}$ LIF for 7 days had no effect on neurosphere number, but decreased sphere size by $75 \%$ (fig. 3A-C). Despite the smaller size of the spheres, LIF increased the proportion of multipotential spheres by 5 -fold. Upon passaging neurospheres after LIF treatment, there was a 2 -fold increase in sphere number, but again the spheres were significantly smaller ( $30 \%$ control; fig. 3F-H). Using the NSA, these data suggest that LIF expands and sustains the self-renewal of multipotential NP(s).

\section{Flow Cytometry Demonstrates that LIF Expands}

Neonatal NSCs, LeX+ Intermediate Progenitors and

Immature Oligodendrocytes

Having established a flow cytometric method that enables the quantification of 8 different types of neural precursors, we used this assay to test the hypothesis that LIF stimulates NSC expansion. The addition of $5 \mathrm{ng} / \mathrm{ml} \mathrm{LIF}$ to defined medium used to grow NPs doubled the percentage of NSCs, increased MP1s (30\%), PFMPs (10\%) and BNAP/GRP1s (19\%; fig. 4). However, LIF also reduced another pool of precursors that we hypothesize are 
Fig. 3. LIF Expands and sustains self-renewing multipotential neonatal neural precursors, neurospheres established from P4-5 C57BL/6 mouse pups were passaged to secondary spheres and amplified in medium containing $20 \mathrm{ng} / \mathrm{ml} \mathrm{EGF,} 20 \mathrm{ng} / \mathrm{ml}$ FGF-2 \pm LIF. A, B Cells were treated with 5 or $20 \mathrm{ng} / \mathrm{ml} \mathrm{rmLIF}$ for $7 \mathrm{DIV}$. Then the number $(\mathbf{A})$ and size $(\mathbf{B})$ of generated neurospheres was quantified. C Representative phase-contrast images of spheres at 7 DIV. D The percentage of multipotential spheres after 6 DIV LIF treatment. E Representative images of progeny immunostained for O4 (red), TuJ1 (green) and GFAP (blue). F, G Number of secondary spheres formed (F) and volume of spheres (G). $\mathbf{H}$ Representative phase contrast images of secondary spheres. Data are representative of 6 independent experiments with error bars representing mean \pm SEM of $n=4$ per experiment. At least 120 spheres were measured per group for volume calculations. ${ }^{* *} \mathrm{p}<0.01 ;{ }^{* *} \mathrm{p}<0.001$ versus control and ${ }^{\ddagger \neq} \mathrm{p}<0.001$ versus 5 ng LIF by Tukey's post hoc test. Scale bars $=100 \mu \mathrm{m}$ in panels $\mathbf{C}$ and $\mathbf{E}$.
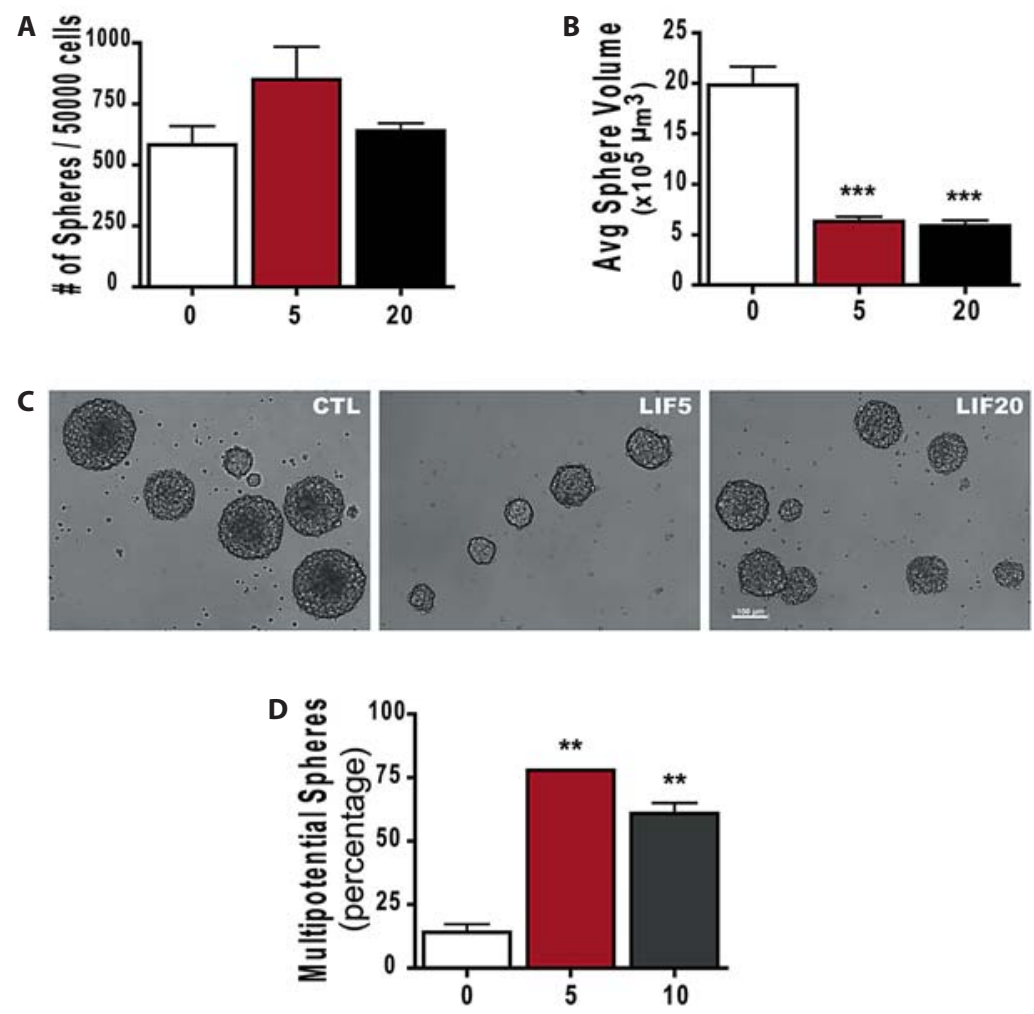

E 04 TUل1 GFAP
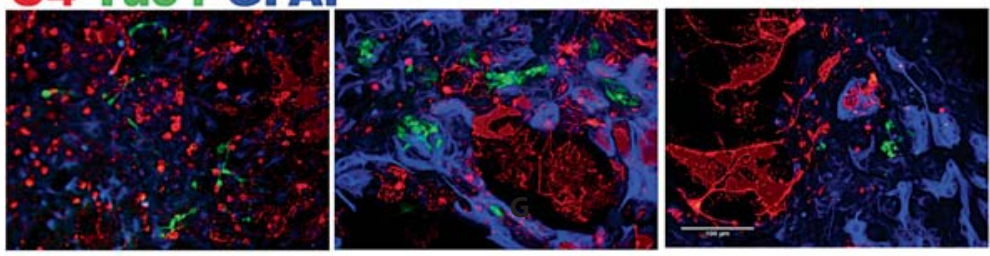

F

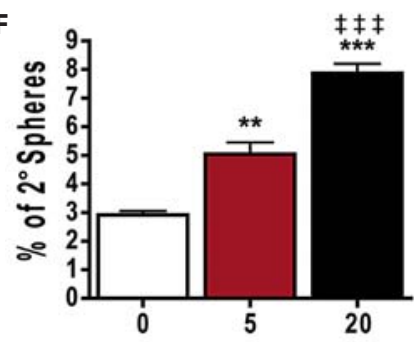

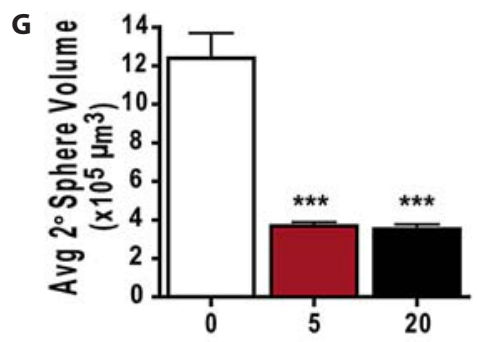
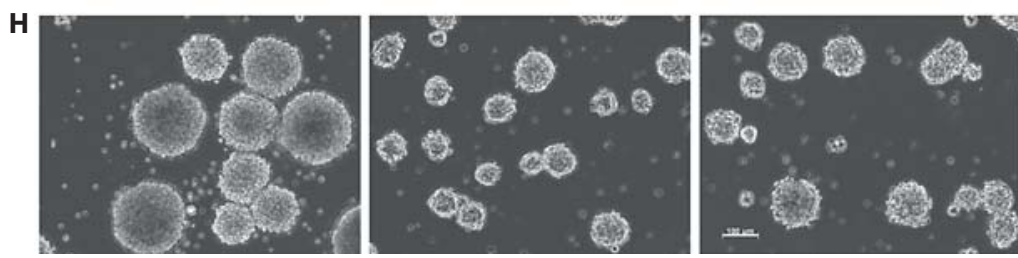
Fig. 4. LIF and CNTF differentially regulate neural precursor homeostasis. A-J Neurospheres established from P4-5 C57BL/6 mouse pups were passaged to secondary spheres and amplified in medium containing $20 \mathrm{ng} / \mathrm{ml} \mathrm{EGF,} 20 \mathrm{ng} / \mathrm{ml} \mathrm{FGF}-2$ with either $5 \mathrm{ng} / \mathrm{ml} \mathrm{rmLIF}$ or $\mathrm{rrCNTF}$ (plus $100 \mathrm{ng} / \mathrm{ml} \mathrm{sCNTF}$ receptor). The proportion of NP subtypes was quantified by flow cytometry, using a NP panel (pie graphs and table): CD133/LeX/NG2/ CD140a/CD24 and an oligodendrocyte (OL) panel (bar graphs): CD133/CD140a/ O4/CD24. 20,000-40,000 live cell events were analyzed after excluding debris and dead cells using DAPI and gating on positively stained cells based on isotype controls. All cells were CD24+. Data represent averages from 3 independent experiments for CTL, and $5 \mathrm{ng} / \mathrm{ml} \mathrm{LIF}$ and CNTF. Table and error bars represent mean percentages \pm SEM. ${ }^{*} \mathrm{p}<0.05 ;{ }^{*} \mathrm{p}<0.01 ;{ }^{* *} \mathrm{p}<$ 0.001 versus control by Tukey's post hoc test.

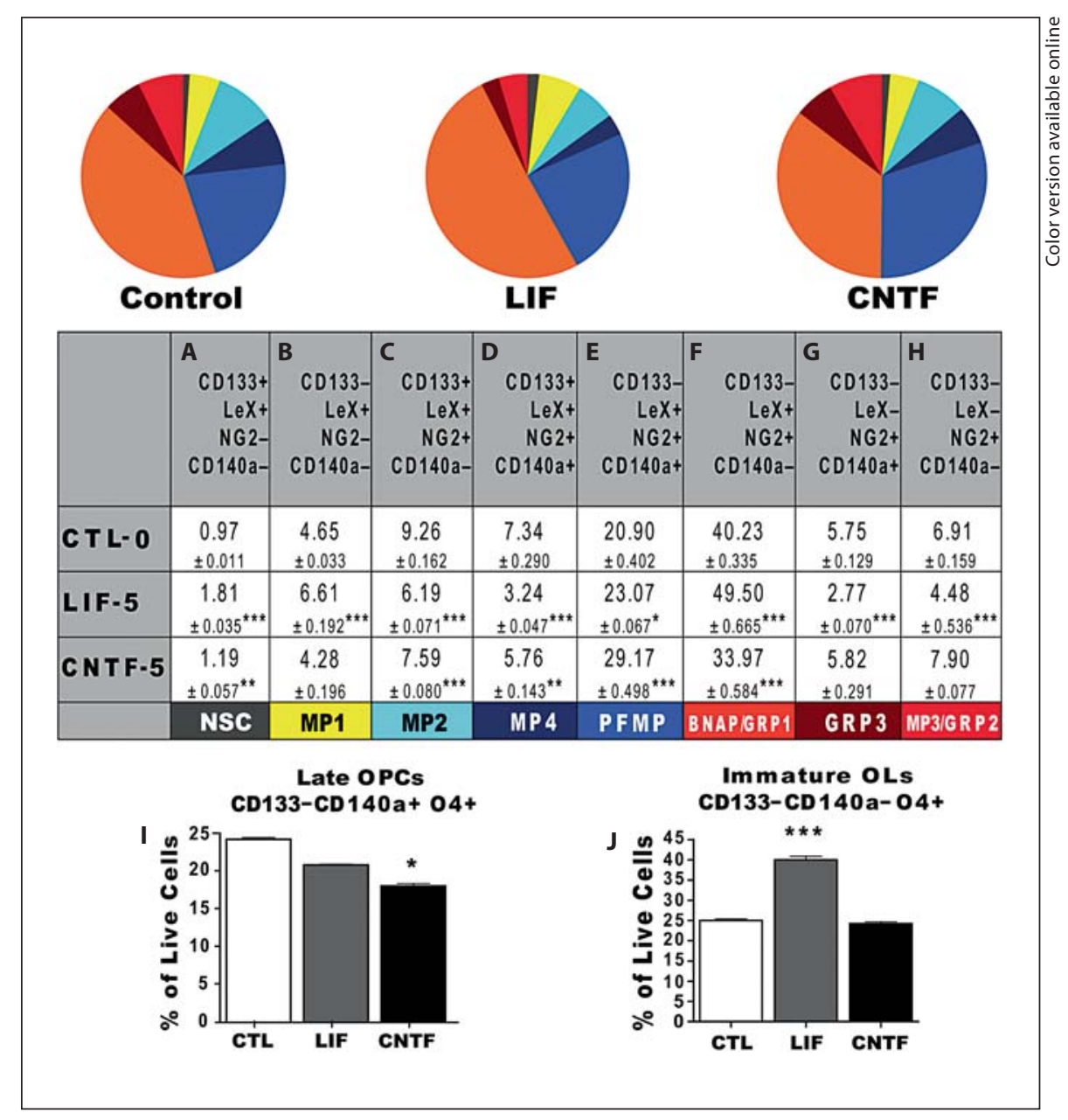

descended from the MP2 progenitor due to their surface marker phenotype: MP2s (33\%), MP4s (55\%) and MP3/ GRP2s (35\%). Unexpectedly, LIF reduced the frequency of GRP3s (52\%; fig. 4). There was no difference by flow cytometry between $5 \mathrm{ng} / \mathrm{ml}$ and $20 \mathrm{ng} / \mathrm{ml}$ of LIF (data not shown). These data indicate that LIF specifically promotes the growth and maintenance of three phenotypically distinct multipotent precursors; NSCs, MP1s and PFMPs, and one mixed population of bipotential progenitors (BNAP/GRP1s), while simultaneously repressing the expansion of a separate set of LIF-nonresponsive progenitors.

Like LIF, CNTF, which is structurally similar, has been reported to regulate NP self-renewal, multipotency and maturation of the oligodendrocyte lineage [28]. However, it has not been established whether this related but distinct cytokine exerts similar or different effects on NPs. Therefore, we used flow cytometry with two multi- marker panels to determine how LIF and CNTF affect NP population dynamics (table 1). These analyses revealed significant differences, but also similarities between LIF and CNTF. As described above, LIF increased the proportion of NSCs, MP1s, PFMPs and BNAP/GRP1s, while it significantly decreased MP2s, MP4s, GRP3s and GRP2s. LIF expanded NSCs and MP1s by 1.5 -fold compared to CNTF (ANOVA, Tukey test, $\mathrm{p}<0.001$; fig. 4A, B). Both cytokines increased PFMPs; and decreased MP2 and MP4 percentages (fig. 4C, D). Using the CD133/ CD140a/O4-panel, LIF increased the production of immature oligodendrocytes (CD133-CD140a-O4+) by $43 \%$ when compared to control and CNTF (ANOVA, Tukey test, $\mathrm{p}<0.001$; fig. 4J). Interestingly, CNTF had no effect on the production of pre- or immature oligodendrocytes. Altogether these data demonstrate that LIF is unique in its ability to expand neonatal NSCs, MP1s, BNAP/GRP1s and immature oligodendrocytes. 
Table 1. Summary of the 2 antibody panels used to characterize neural precursors by flow cytometry

\begin{tabular}{|c|c|c|}
\hline Antibody & Antibody and source & LSRII configuration \\
\hline \multicolumn{3}{|c|}{ Neural precursor panel } \\
\hline CD133-APC & 13A4; eBioscience & 660/20: 633-laser 4 \\
\hline LeX-eFluor 710 & MMA; BD Bioscience & 710/50: 488-laser 1 \\
\hline CD140a-PE & APA5; BioLegend & 575/26: 488-laser 1 \\
\hline NG2-AF700 & AB5320; Millipore & 730/45: 633-laser 4 \\
\hline DAPI & & 450/50: UV-laser 3 \\
\hline \multicolumn{3}{|c|}{ Oligodendrocyte precursor panel } \\
\hline CD133-APC & 13A4; eBioscience & 660/20: 633-laser 4 \\
\hline CD140a-PE & APA5; BioLegend & 575/26: 488-laser 1 \\
\hline O4-eFluor 710 & $\begin{array}{l}\text { anti-mouse IgM PerCP- } \\
\text { eFluor 710; eBioscience }\end{array}$ & 710/50: 488-laser 1 \\
\hline CD24-PE/Cy7 & M1/69; BioLegend & 780/60: 488-laser 1 \\
\hline DAPI & & 450/50: UV-laser 3 \\
\hline
\end{tabular}

Table 2. LIF induces the expression of specific self-renewal genes

\begin{tabular}{lll}
\hline GENE & EFL5/EF & EFL20/EF \\
\hline Klf4 & 6.508 & 7.213 \\
Fbx15 & 3.070 & 2.764 \\
Nanog & 1.876 & 2.306 \\
Sox2 & 1.739 & 2.976 \\
c-Myc & 1.629 & 2.191 \\
Fut9 & 1.294 & 2.311 \\
Dlx2 & 0.813 & 2.180 \\
Sox1 & 0.756 & 1.596 \\
\hline
\end{tabular}

Neural precursor gene expression was analyzed by qPCR after 7 days in control (EF) and LIF-supplemented medium (EFL) at 5 and $20 \mathrm{ng} / \mathrm{ml}$. mRNA levels were measured using QuantiTech primers from Qiagen and SYBR-Green. Levels were normalized to a cDNA pool produced from P5 neonatal SVZ. Values represent average fold increase in LIF-treated cultures from 3 independent experiments.

\section{LIF Increases Self-Renewal Genes and Regulates LeX Expression by FUT9}

LIF increased production of secondary neurospheres and the proportion of NPs expressing the LeX marker, suggesting that this cytokine enhances NP self-renewal. To investigate this possibility, the expression of several stem cell self-renewal genes was assessed. qPCR revealed that spheres treated with 5 and $20 \mathrm{ng} / \mathrm{ml}$ of LIF had increased expression of Klf4, F-box protein 15 (Fbx15),
Nanog, sex-determining region Y-box 2 (Sox2) and cMyc (table 2). At the higher concentration, LIF increased the expression of Sox1 and Dlx2 (table 2). Flow cytometric analysis of the geometric mean fluorescent intensity established that LIF increased LeX expression by $75 \%$ (ANOVA, Tukey test, $\mathrm{p}<0.001$ ). Fut9 is a synthetic enzyme for LeX-expressing proteins and lipids. Fut9 increased in a dose-dependent fashion between 5 and 20 $\mathrm{ng} / \mathrm{ml}$ of LIF (table 2). Overall, these data are consistent with the interpretation that LIF keeps NPs in a self-renewing state by increasing their expression of Fut9, Klf4, Fbx15, Nanog, Sox2 and c-Myc.

\section{LIF Deficiency Decreases NSCs and Immature}

Oligodendrocytes, while Intermediate Progenitors

Accumulate

Neural stem and progenitor cells within the SVZ receive signals from their niche to self-renew, expand and differentiate. Prior studies have shown that LIF is secreted by choroid plexus cells [2] and astrocytes [29], two of the main regulators of the periventricular niche. Despite the recognized important role that LIF exerts on stem cell self-renewal, the SVZ of the LIF null mouse has not been analyzed to determine whether there are fewer NPs and/ or NSCs. Thus, to test the above in vitro model of LIF function, and also to better understand the role of LIF in neural development, the cellular composition of the SVZ of individual LIF knockout and heterozygous neonates were assessed by flow cytometry. SVZs were microdissected from 11-day-old wild-type (WT), LIF heterozygous (Het) and LIF knockout (KO) neonates. The SVZs were dissociated into single cell suspensions and stained for the two panels of NPs described earlier. Flow cytometry revealed that 7 of the 8 phenotypically identified NPs present in neurospheres were identified within the SVZ (MP4 cells were undetectable). As mentioned earlier, some of the NG2+ cells directly sorted from the SVZ generated neurons and glia whereas others only produced glia; therefore, the group of cells with phenotype of CD133-LeXNG2+CD140a-is likely a mixture of two precursors which we will henceforth refer to as MP3/GRP2 cells. By flow cytometry, LIF KO mice displayed a $66 \%$ reduction in NSCs and a $42 \%$ reduction in immature oligodendrocytes compared to wild-type mice (fig. 5A, I), but an increased proportion of MP2s (74\%), BNAP/GRP1s (59\%), MP3/ GRP2s (59\%; fig. 5C, E, G). Surprisingly, LIF Het displayed a similar phenotype as the LIF nulls. These changes in vivo due to the loss of LIF were opposite to those obtained with the gain of LIF studies where there was an expansion in all three bipotential progenitor populations. 
Fig. 5. LIF deficiency disrupts the steadystate balance of SVZ precursors leading to a surplus of intermediate progenitors. A-I SVZs from P11 WT, LIF Het and LIF KO CD1 mice were analyzed by flow cytometry using the NP panel (pie graph and table): CD133/LeX/NG2/CD140a/CD24 and OL panel (bar graphs): CD133/ CD140a/O4/CD24. Six independent animals per genotype (WT, LIF Het and LIF $\mathrm{KO})$ were analyzed ( 3 female and 3 male). 50,000 live cell events were analyzed per animal after excluding debris and dead cell using LIVE/DEAD violet and gating on positively stained cells based on isotype controls. All cells were CD24+. Table and error bars represent mean percentages \pm SEM. ${ }^{*} \mathrm{p}<0.05 ;{ }^{* *} \mathrm{p}<0.01 ;{ }^{* *} \mathrm{p}<0.001$ versus control by Tukey's post hoc test.

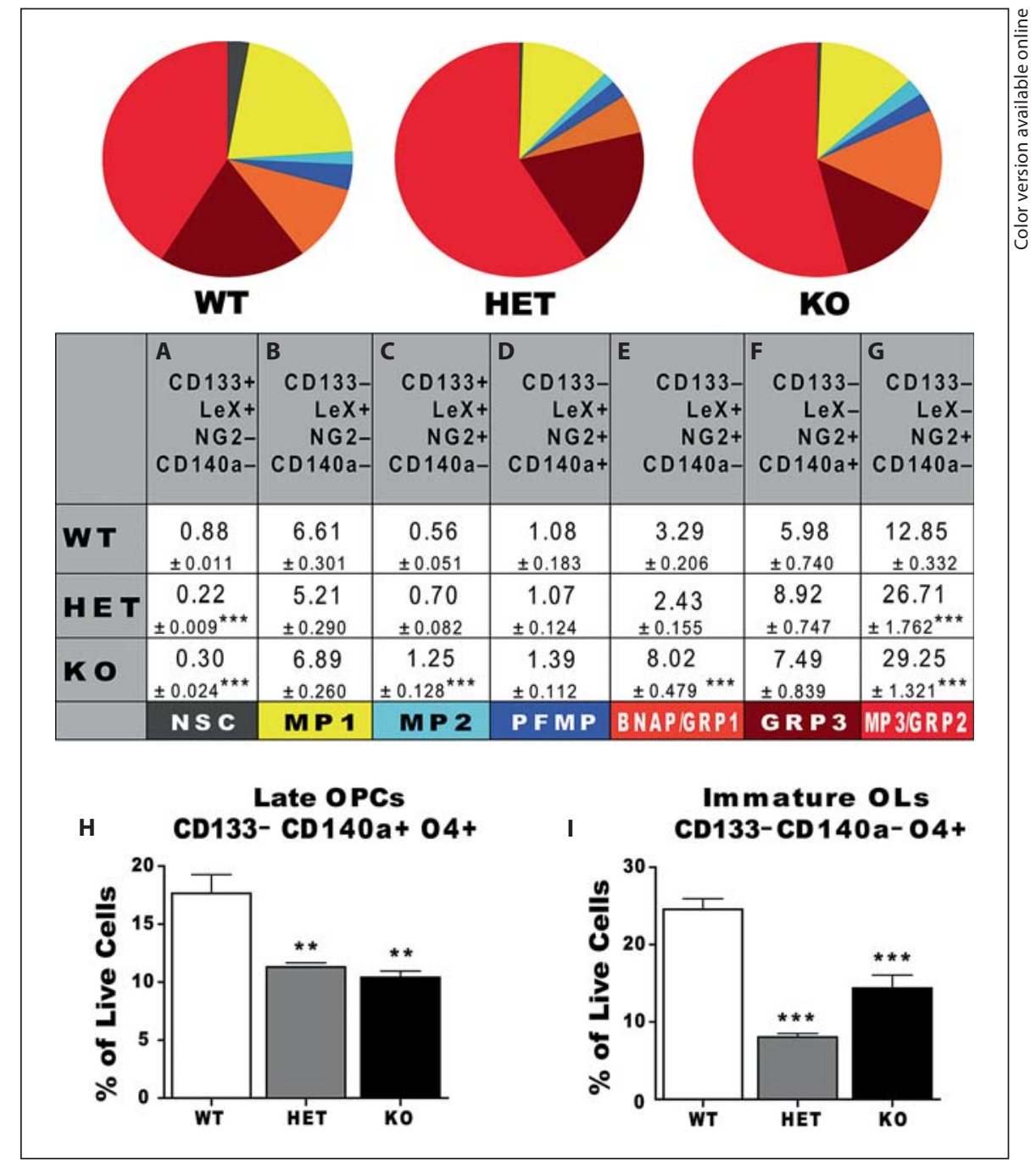

Similar to the in vitro flow cytometry data, CD24 expression was detected in all SVZ populations [14].

Many studies have characterized the adult SVZ as being comprised of 4 classes of precursors: A cells, two types of B cells and C cells. Therefore, it was of interest to compare the composition of the adult mouse SVZ with that of the neonatal SVZ using our multimarker flow cytometry panel. The SVZs from 2-month-old mice were microdissected from the periventricular wall, enzymatically and mechanically dissociated and then layered onto $22 \%$ Percoll to remove debris prior to being stained for the cellsurface markers CD133, LeX, NG2 and CD140a. Flow cytometry revealed that the multimarker-panel identified seven distinct progenitors that were present at the following frequencies: NSCs (0.23 $\pm 0.08 \%)$, MP1 (10.99 $\pm 2.89 \%)$, MP2 (0.40 $\pm 0.20 \%), \operatorname{PFMP}(0.17 \pm 0.11 \%)$, BNAP/GRP1 (3.48 $\pm 2.28 \%)$, MP3/GRP2 (8.02 \pm 0.53$)$ and GRP3 $(0.19 \pm 0.03 \%)$. These results are averages from 3 separate analyses where the SVZs from 8 animals were pooled for each analysis in order to obtain at least 1 $\times 10^{6}$ viable cells for flow cytometry.

Altogether, these multimarker flow cytometry studies have defined important new tools to analyze NPs both in vitro and in vivo. These panels have identified new types of neural precursors, demonstrated that both the neonatal and adult SVZ are comprised of complex mosaic of neural precursors and demonstrated the important role that LIF plays in regulating neonatal NPs, especially in NSC maintenance and immature oligodendrocyte production. 
Fig. 6. LIF responsiveness on neonatal SVZ neural precursor diversity. This schematic summarizes the diverse set of sorted neonatal NPs, their fate and their responsiveness to LIF. NPs that responded to LIF include NSCs, MP1s and PFMFs which differentiate into neurons, two types of phenotypically distinct astrocytes and oligodendrocytes; BNAP/GRP1 which differentiate into neurons and 2 types of astrocytes (BNAP) or oligodendrocytes and 2 types of astrocytes (GRP1). Sorted NPs unresponsive to LIF include MP2s and MP4s which differentiate into neurons, astrocytes and oligodendrocytes; GRP2s and GRP3s which differentiate into astrocytes and oligodendrocytes. Curved arrows above NPs depict sustained self-renewal in response to LIF.

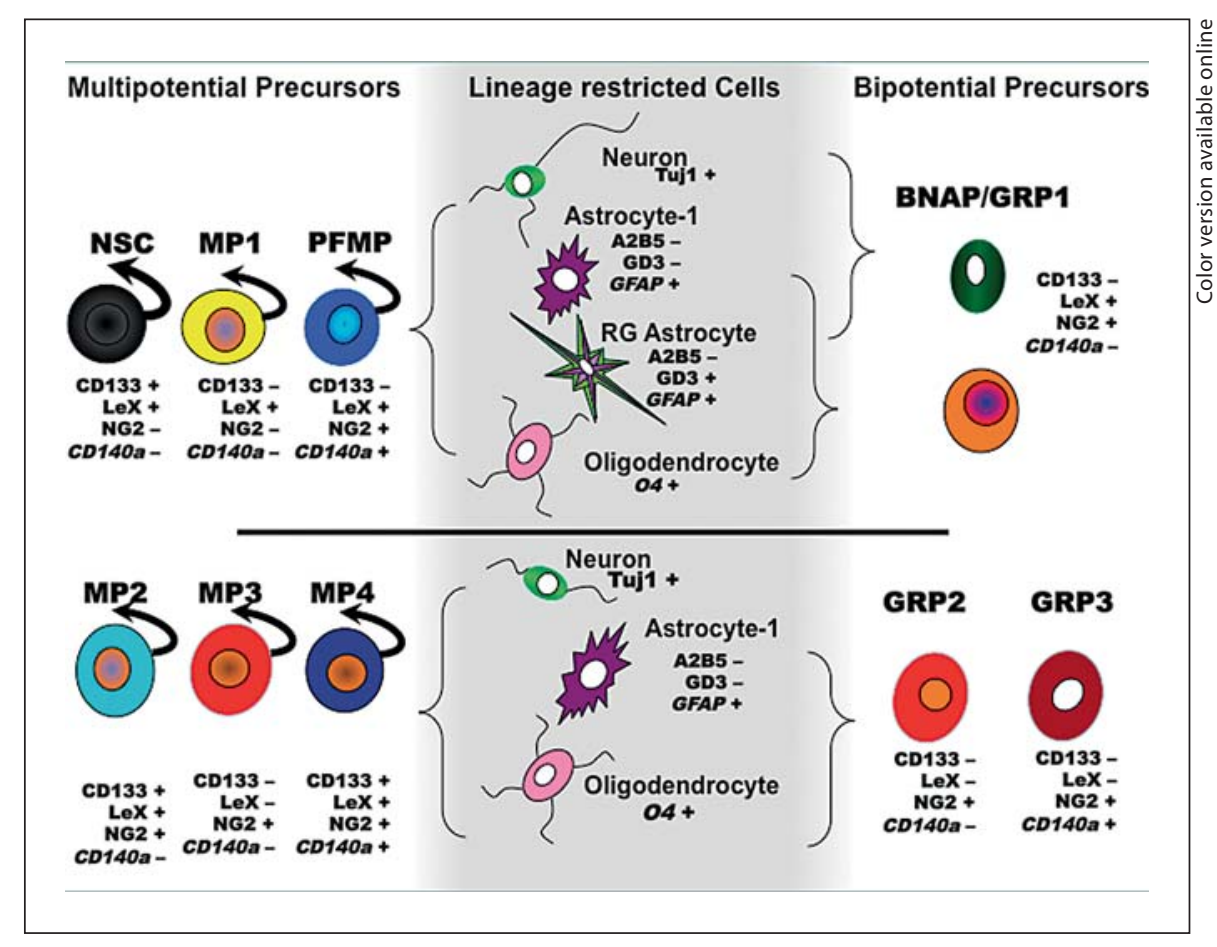

\section{Discussion}

To evaluate the outcomes of perturbing the signals that regulate neural stem cells and progenitors, sensitive and reproducible methods of quantifying the relative numbers of stem cells and progenitors are needed. Using multimarker flow cytometry we have established the means to isolate NSCs and 7 types of intermediate neural progenitors. Studies of the fetal and neonatal SVZ foreshadowed the diversity that we now document $[16,30,31]$. By defining precursors as either positive or negative for 1 of 4 cell-surface antigens, 7 classes of cells were partitioned from dissociates of the neonatal SVZ. The descendants that each precursor produced are summarized in figure 6. NSCs (CD133+LeX+NG2-CD140a-CD24 $4^{\text {lo }}$ ) represented a small percentage of the total cells, as expected from estimates of their prevalence of $1 \%$ as previously reported within neurospheres [32]. The abundance of NSCs in the adult SVZ agrees with previous estimates of $0.2-0.4 \%$ [33]. That the value we report for NSC abundance within the neonatal SVZ is higher than that reported for the adult should not be surprising since the percentage of NSCs decreases with age [34]. The NSCs were extremely slowly dividing cells and they generated smaller spheres than the other NPs. This observed relative quiescence agrees with the estimates of the cell cycle time for a progenitor as $13 \mathrm{~h}$, while for a NSC it is $2-3$ weeks in vivo [35]. In summing the percentages of identified cells in the P11 SVZ (from both the table as well as from the two graphs in fig. 5), our flow cytometric analysis accounts for $73 \%$ of the total cells. Missing from our FACS and flow analysis panel are cell-surface markers that identify precursors committed to the astrocyte lineage and precursors that are committed neuroblasts. Previous retroviral lineage tracing experiments of SVZ cells have established that approximately $20 \%$ of the dividing cells within the P14 SVZ are restricted to the astrocyte lineage and $6 \%$ are restricted neuroblasts; thus, these two populations of precursors likely comprise the bulk of the cells that were unclassified using our 4-color flow panel [31]. Studies are underway to incorporate additional surface markers for these progenitors into a larger multicolor panel.

Our data corroborate previous flow cytometric analyses that demonstrated that CD24 is found on all NPs. Several studies have reported that NSCs and primitive progenitors express low levels of CD24 [4, 19], whereas others have reported that NSCs are CD24-negative [7, 11]. CD24 is sensitive to enzymatic degradation; therefore, using gentle enzymes like collagenase plus dispase (in liberase [19]) or collagenase plus hyaluronidase [4], will retain the CD24 antigen. 
Of the 4 sorted multipotential precursors (excluding MP4s because they were not found in vivo), one expressed the PDGFRa, which has been predominantly associated with oligodendrocyte progenitors. This CD133$\mathrm{LeX}+\mathrm{NG} 2+\mathrm{CD} 140 \mathrm{a}+$ cell (PFMP) is likely the NG2+ multipotential precursor that has been isolated from the embryonic forebrain [36] and from neonatal and adult SVZs $[37,38]$. Recent fate-mapping studies have suggested that these multipotential PDGFRa+ precursors produce pyramidal neurons of the piriform cortex [37, 39]. Interestingly, we also found that the PFMPs did not self-renew when grown in medium supplemented with EGF and FGF2, but proliferated and self-renewed when placed into medium containing PDGF-AA and FGF2, similar to results obtained by Chojnacki et al. [36]. In comparing the neonatal versus the adult SVZ, the PFMPs showed the largest reduction with age.

The existence of bipotential precursors and especially glial-restricted precursors that can generate astrocytes and oligodendrocytes has been a subject of much debate $[40,41]$. Originally shown to be present within the SVZ of the neonate using retroviral fate mapping analyses in vivo [42], these cells have since been found within the spinal cord [20]. More recently, two GRPs were isolated from the embryonic telencephalon, having an A2B5+NG2-CD140a- phenotype [43]. Extending these earlier studies, our data reveal the existence of 3 pools of bipotential progenitors within the neonatal SVZ: CD133LeX+NG2+ CD140a- (BNAP/GRP1), CD133-LeX$\mathrm{NG} 2+\mathrm{CD} 140 \mathrm{a}+(\mathrm{GRP} 3)$ and CD133-LeX-NG2+CD140a(GRP2). GRPs isolated from spinal cord, optic nerve and from the ventral and dorsal telencephalon depend upon FGFs for survival and proliferation. In agreement with these studies, only one of the three GRPs expressed CD140a (GRP3) which is likely the 'Pre-O-2A' cell previously described in cultures of rat telencephon by Ben-Hur et al. [44] and by Grinspan et al. [45]. Studies using transgenic mice have revealed two NG2+ populations (PlpNG2+CD140+ and Plp+NG2+CD140a-) that are located within the neonatal SVZ and appear to be closely related having similar morphology, migratory and proliferative capacity $[46,47]$. All of the GRPs we isolated were NG2+ immunoreactive. Using NG2 reporter mice, a study found that in vitro NG2 cells produced oligodendrocytes, astrocytes, while in vivo, they produced myelinating oligodendrocytes and protoplasmic astrocytes [48].

LIF is essential for maintaining self-renewal in mESC cultures and, in addition, it sustains cortical, embryonic and adult SVZ NPs in vitro $[25,26,49]$. These studies have concluded that LIF enhances self-renewal by promoting
Table 3. Summary of in vitro versus in vivo effects of LIF on neural precursor population dynamics

\begin{tabular}{lllllllll}
\hline \multirow{2}{*}{ Cell } & \multicolumn{3}{l}{ Surface marker ID } & & & \multicolumn{2}{c}{ LIF -} \\
\cline { 2 - 3 } & CD133 & LeX & NG2 & CD140a & & in vitro & in vivo \\
\hline NSC & + & + & - & - & & up & down \\
MP1 & - & + & - & - & & up & UC \\
MP2 & + & + & + & - & & down & up \\
MP4 & + & + & + & - & & down & ND \\
PFMP & - & + & + & + & & up & UC \\
BNAP/GRP1 & - & + & + & - & & up & up \\
GRP3 & - & - & + & + & & down & UC \\
MP3/GRP2 & - & - & + & - & & down & up \\
Pre-OL & - & - & - & + & & UC & down \\
Im-OL & - & - & - & - & & up & down \\
\hline
\end{tabular}

Flow cytometry data are summarized from 7-day in vitro treatment with $\mathrm{rmLIF}$ at $5 \mathrm{ng} / \mathrm{ml}$ and from LIF null mice SVZs. UC indicates no change between control and experimental. Some cell types were identified in one environment, but were not detected (ND) in the other.

symmetric expansions at the expense of asymmetric divisions. If LIF only affected NSCs, then one would predict that in the absence of LIF there would be a reduction in NSCs and an increase in all of the intermediate precursors and that the opposite would be obtained with LIF supplementation; however, this is not what we observed. All previous studies used the NSA, and assumed that an increase in self-renewal and multipotential spheres reflected an increase in NSCs. These earlier studies were indeed partially correct in that LIF maintains NSCs, but our data reveal that LIF expands several LIF-responsive precursors that appear to be linearly related and which consist of two MPs (MP1 and PFMP) and a mixed bipotential neuronal-glial population (BNAP/GRP1; table 3). Our data also suggest that LIF expands precursors whose progeny include radial glial-like astrocytes, reminiscent of previous observations [22]. Our data further suggest that LIF blocks MP2 expansion, and thus, inhibits production of its progeny (GRP2). With LIF deficiency, NSCs and immature oligodendrocytes are primarily affected. Accompanying the significant reduction in NSCs, there is an expansion of MP2s and their progeny. However, the upsurge of intermediate bipotential progenitors is not completely because the NSCs have lost their ability to self-renew, as concluded from studies of LIFR nulls [2]. The expansion of these restricted progenitors is also due to their inability to further differentiate into immature oligodendrocytes. This accumulation of NG2+ cells was also seen within the optic 
nerves of LIF nulls at P10 [50]. However, based on their antigen expression and differentiation capacity, the NG2 cells that accumulated within the SVZ are likely less differentiated than those that accumulate in the optic nerve.

In conclusion, we have established the means to isolate a NSC and 7 types of intermediate NPs by flow cytometry. Using FACS we have begun to gain insights into the growth factor requirements of each type of intermediate progenitor as well as the progeny that they produce. Our studies suggest that there are at least three multipotential progenitors within the neonatal SVZ that can each produce neurons, astrocytes and oligodendrocytes. We have shown that these precursors are differentially regulated by LIF and that the types of glial cells that they produce are distinct. It is likely that each precursor also produces unique types of neurons, which we did not attempt to evaluate. Clearly, many more studies will be required to fully understand the intrinsic properties and lineage relationships of each precursor type and how they respond to en- vironmental cues. Given the interest in cancer stem cells, we anticipate that having the ability to isolate NPs at different stages of developmental restriction will provide new insights into the origins of specific brain tumors, such as glioblastoma. Finally, these studies are not only informative for understanding neural development, but also for promoting nervous system regeneration and repair.

\section{Acknowledgements}

We thank C. Stewart for permission to use his LIF null mice, R.D. Fields for shipping the LIF mice, S. Singh and D. Stein for flow cytometry assistance, T. Galenkamp for cell sorting; J. Goldman for GD3 antibody, and A. White and D. Lazzarino for editing the manuscript. This work was presented in part at the American Society for Neurochemistry meeting [51] and was supported by grants from the National Institutes of Health, MH59950 and HD052064, and the Leducq Foundation awarded to S.W.L, along with a NIH NINDS Training Grant fellowship, NS051157 awarded to K.D.B.

\section{References}

1 Sanai N, Nguyen T, Ihrie RA, Mirzadeh Z, Tsai HH, Wong M, Gupta N, Berger MS, Huang E, Garcia-Verdugo JM, Rowitch DH, Alvarez-Buylla A: Corridors of migrating neurons in the human brain and their decline during infancy. Nature 2011;478:382386.

-2 Gregg C, Weiss S: CNTF/lif/gp130 receptor complex signaling maintains a VZ precursor differentiation gradient in the developing ventral forebrain. Development 2005;132: 565-578.

$\checkmark 3$ Vescovi AL, Reynolds BA, Fraser DD, Weiss $S$ : BFGF regulates the proliferative fate of unipotent (neuronal) and bipotent (neuronal/astroglial) EGF-generated CNS progenitor cells. Neuron 1993;11:951-966.

4 Uchida N, Buck DW, He D, Reitsma MJ, Masek M, Phan TV, Tsukamoto AS, Gage FH, Weissman IL: Direct isolation of human central nervous system stem cells. Proc Natl Acad Sci USA 2000;97:14720-14725.

$>5$ Sawamoto K, Nakao N, Kakishita K, Ogawa Y, Toyama Y, Yamamoto A, Yamaguchi M, Mori K, Goldman SA, Itakura T, Okano H: Generation of dopaminergic neurons in the adult brain from mesencephalic precursor cells labeled with a nestin-GFP transgene. J Neurosci 2001;21:3895-3903.

-6 Coskun V, Wu H, Blanchi B, Tsao S, Kim K, Zhao J, Biancotti JC, Hutnick L, Krueger RC Jr, Fan G, de Vellis J, Sun YE: CD133+ neural stem cells in the ependyma of mammalian postnatal forebrain. Proc Natl Acad Sci USA 2008;105:1026-1031
7 Capela A, Temple S: Lex/ssea-1 is expressed by adult mouse CNS stem cells, identifying them as nonependymal. Neuron 2002;35: 865-875

-8 Jablonska B, Aguirre A, Vandenbosch R, Belachew S, Berthet C, Kaldis P, Gallo V: Cdk2 is critical for proliferation and self-renewal of neural progenitor cells in the adult subventricular zone. J Cell Biol 2007;179:12311245.

$\checkmark 9$ Maric D, Maric I, Chang YH, Barker JL: Prospective cell sorting of embryonic rat neural stem cells and neuronal and glial progenitors reveals selective effects of basic fibroblast growth factor and epidermal growth factor on self-renewal and differentiation. J Neurosci 2003;23:240-251.

10 Rietze RL, Valcanis H, Brooker GF, Thomas T, Voss AK, Bartlett PF: Purification of a pluripotent neural stem cell from the adult mouse brain. Nature 2001;412:736-739.

11 Pastrana E, Cheng LC, Doetsch F: Simultaneous prospective purification of adult subventricular zone neural stem cells and their progeny. Proc Natl Acad Sci USA 2009;106: 6387-6392.

12 Beckervordersandforth R, Tripathi P, Ninkovic J, Bayam E, Lepier A, Stempfhuber B, Kirchhoff F, Hirrlinger J, Haslinger A, Lie DC, Beckers J, Yoder B, Irmler M, Gotz M: In vivo fate mapping and expression analysis reveals molecular hallmarks of prospectively isolated adult neural stem cells. Cell Stem Cell 2010;7:744-758 $\checkmark 13$ Merkle FT, Tramontin AD, Garcia-Verdugo JM, Alvarez-Buylla A: Radial glia give rise to adult neural stem cells in the subventricular zone. Proc Natl Acad Sci USA 2004;101: 17528-17532.

14 Buono KD: Analyses of mouse neural precursor responses to leukemia inhibitor factor and hypoxia/ischemia: Graduate School of Biomedical Sciences. Newark, University of Medicine and Dentistry of New Jersey; PhD Diss, 2011, pp 1-200.

15 Lim DA, Tramontin AD, Trevejo JM, Herrera DG, Garcia-Verdugo JM, Alvarez-Buylla A: Noggin antagonizes bmp signaling to create a niche for adult neurogenesis. Neuron 2000;28:713-726.

16 Gal JS, Morozov YM, Ayoub AE, Chatterjee M, Rakic P, Haydar TF: Molecular and morphological heterogeneity of neural precursors in the mouse neocortical proliferative zones. J Neurosci 2006;26:1045-1056.

17 Doetsch F, Garcia-Verdugo JM, AlvarezBuylla A: Cellular composition and threedimensional organization of the subventricular germinal zone in the adult mammalian brain. J Neurosci 1997;17:5046-5061.

18 Levison SW, Goldman JE: Multipotential and lineage restricted precursors coexist in the mammalian perinatal subventricular zone. J Neurosci Res 1997;48:83-94.

19 Panchision DM, Chen HL, Pistollato F, Papini D, Ni HT, Hawley TS: Optimized flow cytometric analysis of central nervous system tissue reveals novel functional relationships among cells expressing CD133, CD15, and CD24. Stem Cells 2007;25:1560-1570. 
-20 Goldman JE, Hirano M, Yu RK, Seyfried TN: GD3 ganglioside is a glycolipid characteristic of immature neuroectodermal cells. J Neuroimmunol 1984;7:179-192.

-21 Rao MS, Mayer-Proschel M: Glial-restricted precursors are derived from multipotent neuroepithelial stem cells. Dev Biol 1997; 188:48-63.

22 Bonaguidi MA, McGuire T, Hu M, Kan L, Samanta J, Kessler JA: LIF and BMP signaling generate separate and discrete types of GFAP-expressing cells. Development 2005; 132:5503-5514.

23 Vaysse PJ, Goldman JE: A distinct type of GD3+, flat astrocyte in rat CNS cultures. J Neurosci 1992;12:330-337.

-24 Wright LS, Li J, Caldwell MA, Wallace K, Johnson JA, Svendsen CN: Gene expression in human neural stem cells: effects of leukemia inhibitory factor. J Neurochem 2003;86: 179-195.

25 Pitman M, Emery B, Binder M, Wang S, Butzkueven H, Kilpatrick TJ: Lif receptor signaling modulates neural stem cell renewal. Mol Cell Neurosci 2004;27:255-266.

26 Bauer S, Patterson PH: Leukemia inhibitory factor promotes neural stem cell self-renewal in the adult brain. J Neurosci 2006;26: 12089-12099.

27 Hilton DJ, Nicola NA: Kinetic analyses of the binding of leukemia inhibitory factor to receptor on cells and membranes and in detergent solution. J Biol Chem 1992;267:1023810247.

-28 Muller S, Chakrapani BP, Schwegler H, Hofmann HD, Kirsch M: Neurogenesis in the dentate gyrus depends on ciliary neurotrophic factor and signal transducer and activator of transcription 3 signaling. Stem Cells 2009;27:431-441.

-29 Ishibashi T, Dakin KA, Stevens B, Lee PR, Kozlov SV, Stewart CL, Fields RD: Astrocytes promote myelination in response to electrical impulses. Neuron 2006;49:823832.

30 Levison SW, Goldman JE: Both oligodendrocytes and astrocytes develop from progenitors in the subventricular zone of postnatal rat forebrain. Neuron 1993;10:201-212.
Young GM, Levison SW: Persistence of multipotential progenitors in the juvenile rat subventricular zone. Dev Neurosci 1996;18: 255-265.

32 Reynolds BA, Rietze RL: Neural stem cells and neurospheres - re-evaluating the relationship. Nat Methods 2005;2:333-336.

33 Morshead CM, Craig CG, van der Kooy D: In vivo clonal analyses reveal the properties of endogenous neural stem cell proliferation in the adult mammalian forebrain. Development 1998;125:2251-2261.

34 Molofsky AV, Slutsky SG, Joseph NM, He S, Pardal R, Krishnamurthy J, Sharpless NE, Morrison SJ: Increasing pl6ink4a expression decreases forebrain progenitors and neurogenesis during ageing. Nature 2006;443: 448-452.

35 Morshead CM, Reynolds BA, Craig CG, McBurney MW, Staines WA, Morassutti D, Weiss S, Van der Kooy D: Neural stem cells in the adult mammalian forebrain: a relatively quiescent subpopulation of subependymal cells. Neuron 1994;13:1071-1082.

36 Chojnacki A, Weiss S: Isolation of a novel platelet-derived growth factor-responsive precursor from the embryonic ventral forebrain. J Neurosci 2004;24:10888-10899.

- 37 Rivers LE, Young KM, Rizzi M, Jamen F, Psachoulia K, Wade A, Kessaris N, Richardson WD: PDGFRa/NG2 glia generate myelinating oligodendrocytes and piriform projection neurons in adult mice. Nat Neurosci 2008;11:1392-1401.

38 Chojnacki A, Mak G, Weiss S: Pdgfralpha expression distinguishes GFAP-expressing neural stem cells from PDGF-responsive neural precursors in the adult periventricular area. J Neurosci 2011;31:9503-9512.

39 Guo F, Maeda Y, Ma J, Xu J, Horiuchi M, Miers L, Vaccarino F, Pleasure D: Pyramidal neurons are generated from oligodendroglial progenitor cells in adult piriform cortex. J Neurosci 2010;30:12036-12049.

40 Liu Y, Rao M: Oligodendrocytes, GRPS and MNOPS. Trends Neurosci 2003;26:410-412.

41 Richardson WD, Kessaris N, Pringle N: Oligodendrocyte wars. Nat Rev Neurosci 2006; 7:11-18.
42 Levison SW, Chuang C, Abramson BJ, Goldman JE: The migrational patterns and developmental fates of glial precursors in the rat subventricular zone are temporally regulated. Development 1993;119:611-622.

43 Strathmann FG, Wang X, Mayer-Proschel M: Identification of two novel glial-restricted cell populations in the embryonic telencephalon arising from unique origins. BMC Dev Biol 2007;7:33.

44 Ben-Hur T, Rogister B, Murray K, Rougon G, Dubois-Dalcq M: Growth and fate of PSA-NCAM+ precursors of the postnatal brain. J Neurosci 1998;18:5777-5788.

45 Grinspan JB, Stern JL, Pustilnik SM, Pleasure D: Cerebral white matter contains PDGF-responsive precursors to O2A cells. J Neurosci 1990;10:1866-1873.

46 Mallon BS, Shick HE, Kidd GJ, Macklin WB: Proteolipid promoter activity distinguishes two populations of NG2-positive cells throughout neonatal cortical development. J Neurosci 2002;22:876-885.

- 47 Ivanova A, Nakahira E, Kagawa T, Oba A, Wada T, Takebayashi H, Spassky N, Levine J, Zalc B, Ikenaka K: Evidence for a second wave of oligodendrogenesis in the postnatal cerebral cortex of the mouse. J Neurosci Res 2003;73:581-592.

48 Zhu X, Bergles DE, Nishiyama A: NG2 cells generate both oligodendrocytes and gray matter astrocytes. Development 2008; 135 : 145-157.

49 Hatta T, Moriyama K, Nakashima K, Taga T, Otani H: The role of gp130 in cerebral cortical development: in vivo functional analysis in a mouse exo utero system. J Neurosci 2002;22:5516-5524.

50 Ishibashi T, Lee PR, Baba H, Fields RD: Leukemia inhibitory factor regulates the timing of oligodendrocyte development and myelination in the postnatal optic nerve. J Neurosci Res 2009;87:3343-3355.

51 Buono KD, Levison SW: Lif sustains the selfrenewal of tripotential svz precursors while inhibiting the production of linage restricted progenitors. Trans 41st Am Soc Neurochemistry Meeting, Santa Fe, 2010. 